\title{
Colloidally-induced fines release in porous media
}

\author{
Kartic C. Khilar ${ }^{1}$, R.N. Vaidya ${ }^{2}$ and H.S. Fogler ${ }^{2,3}$ \\ 'Department of Chemical Engineering, Indian Institute of Technology, Bombay Powai, Bombay, 400076 (India) \\ ${ }^{2}$ Department of Chemical Engineering, The University of Michigan, Ann Arbor, Michigan 48109-2136 (U.S.A.)
}

(Accepted after revision June 9, 1989)

\begin{abstract}
Khilar, K.C., Vaidya, R.N. and Fogler, H.S., 1990. Colloidally-induced fines release in porous media. J. Pet. Sci. Eng., 4: 213-221.

A critical value of the total ionic strength (CTIS) has been found to exist for mixed salt solutions flowing in porous media. If the ionic strength drops below this value, significant amounts of fines are released in-situ due to colloidal forces, causing drastic formation damage. For a $\mathrm{NaCl} / \mathrm{CaCl}_{2}$ system, the CTIS is strongly dependent on the relative amount of $\mathrm{CaCl}_{2}$ present in the solution. The concept of a critical salt concentration $(C S C)$ and the analysis based on DLVO theory has been extended to mixed salt systems to estimate the CTIS. The difference between critical flocculation concentration $(C F C)$, and the present definition of CTIS has been pointed out. Predictions of this analysis are consistent with experimental observations.
\end{abstract}

\section{Introduction}

Colloidally-induced release and migration in porous media is important in numerous processes such as enhanced oil recovery, migration of organic waste from landfills, regeneration of filter beds, and erosion of earthen embankments (Khilar and Fogler, 1984, 1987; Khilar et al., 1985). The phenomenon of colloidally-induced fines migration is of significant importance in the petroleum industry as these released fines can migrate and plug regions in the formation causing damage and hence reduction in production. A number of studies using single salt systems $(\mathrm{NaCl}, \mathrm{KCl}$, etc.) have conclusively shown that colloidallyinduced fines release is a threshold type of process that can occur when the salt concentration of the flowing solution decreases below a threshold (or a critical) value known as critical salt concentration (CSC) (Quirk and

\footnotetext{
${ }^{3}$ Author to whom all correspondence should be addressed.
}

Schofield, 1955; Rowell et al., 1969; Hardcastle and Mitchell, 1974; Kolakowski and Matijevic, 1979; Khilar and Fogler, 1984). The latest of these studies has addressed the concept of critical salt concentration in detail and an experimental method has also been proposed to determine $C S C$ for fines migration in Berea sandstone (Khilar and Fogler, 1984). The migrating fines in Berea sandstone were found predominantly to be kaolinite clay. In addition, an analysis has been formulated delineating the effects of flowrate, $\mathrm{pH}$, temperature and, charge and size of cation on CSC in a single salt system. This analysis is based on DLVO theory of stability of lyphobic colloids and the CSC is analogous to the critical flocculation concentration (CFC) in colloid sol stability (Hiemenz, 1986).

Studies have been reported on colloidallyinduced fines migration with a mixed salt system of $\mathrm{NaCl} / \mathrm{CaCl}_{2}$ (Quirk and Schofield, 1955; Jones, 1964; Kia et al., 1987b). These studies primarily emphasize the importance of 
Nomenclature

\begin{tabular}{|c|c|c|c|}
\hline$a$ & radius of sphere & Subscripts & \\
\hline .4 & Hamaker constant & $i, j$ & species, $(1,2 .)$. \\
\hline$e$ & electronic charge & LVA & London-Van der Waals \\
\hline$F$ & force & BR & Born repulsion \\
\hline$h$ & distance of separation & DLR & Double layer \\
\hline$I$ & total ionic strength & HR & hydrodynamic \\
\hline$k$ & Boltzman constant & $\mathrm{T}$ & total \\
\hline$n$ & bulk concentration of ions & & \\
\hline$T$ & temperature & Acronyms & \\
\hline$I^{-}$ & potential energy & $C F C$ & Critical Flocculation Concentration \\
\hline l. & dimensionless potential (Eq. $5 \mathrm{c}$ ) & $C S C$ & Critical Salt Concentration \\
\hline$z$ & valency of the ion & $C T I S$ & Critical Total Ionic Strength \\
\hline & & DLVO & Deryaguin-Landau-Verwey-Overbeek \\
\hline \multicolumn{4}{|c|}{ Greek simbols } \\
\hline$\epsilon$ & permitivity of medium & & \\
\hline$\kappa$ & Debye Huckel parameter (Eq. 5 b) & & \\
\hline$\sigma$ & Born repulsion parameter & & \\
\hline$\zeta$ & zeta potential & & \\
\hline$\psi$ & surface potential & & \\
\hline & ent C.G.S. units) & & \\
\hline
\end{tabular}

the presence of a minimum amount of $\mathrm{Ca}^{2+}$ ions in solution or on the surface of the fines (clay) to prevent their release and migration. Quirk and Schofield (1955) have observed that soil permeability decreases due to the clay swelling* and dispersion when the concentration of $\mathrm{Ca}^{2+}$ ions in the mixed salt solution decreases below a threshold value of $2.5 \times 10^{-4}$ $M$. Their data showed that this threshold value is independent of the concentration of $\mathrm{Na}^{+}$in the solution; which is rather unconvincing. Recent work of Kia et al. (1987b) focuses on the amount of $\mathrm{Ca}^{2+}$ ion on the surface rather than that in the bulk solution. This is a more reasonable approach, because the amount of $\mathrm{Ca}^{2+}$ ions on the surface of the fines determines the zeta potential of the fines which in turn controls the release process. Kia et al. have shown that if the solution composition is adjusted so that coverage on the surface by cal-

\footnotetext{
*Reduction in permeability due to clay swelling occurs because of reduction in flow cross-sectional area due to volume changes of the clay. In fines migration, the clay particles detach from the pore walls and migrate with the fluid until they are captured at pore constrictions, thereby reducing the flow cross-sectional area.
}

cium ions is greater than a critical value of $75 \%$, then the zeta potential is sufficiently reduced for the prevention of colloidally-induced fines release. The surface coverage of calcium ions depends strongly on the total ionic strength as well as on the calcium ionic fraction or percentage in the solution. Consequently, the threshold value of the concentration of $\mathrm{Ca}^{2+}$ to prevent fines release must depend on the mole percentage of calcium in the solution. Experimental work concerning a critical total ionic strength (CTIS) of a mixed salt system, the percentage of calcium in solution and its relationship with the phenomenon of colloidally-induced fines migration has not been reported, nor has an analysis been put forth that can be used to estimate the CTIS. This information is useful in many chemical, environmental and petroleum engineering operations involving flow of mixed salt solutions through a porous medium.

Continuing our earlier work on the CSC (Khilar and Fogler, 1984) we show here that there exists a critical total ionic strength $(C T I S)$, below which colloidally-induced fines release may occur in Berea sandstone. We have 
expanded our earlier analysis of the $C S C$ to mixed salt systems consisting of symmetric and unsymmetric electrolytes. In a $\mathrm{NaCl} / \mathrm{CaCl}_{2}$ system, the CTIS strongly depends on the relative amount of $\mathrm{CaCl}_{2}$ present in the solution (calcium molar percentage, $\% \mathrm{Ca}$ ). For example in a $5 \%$ calcium and $95 \%$ sodium solution, the CTIS is $0.025 \mathrm{M}$ while it decreases significantly to $0.005 M$ for a $10 \%$ calcium and $90 \%$ sodium solution. As we will soon see the predictions using this analysis agree well with the experimental data.

\section{Measurement of the critical total ionic strength (CTIS)}

A schematic of the experimental system is shown in Fig. 1. It consists of a positive displacement pump for fluid injection, a Hassler cell in which the core is contained and, pressure and concentration measuring devices. For a constant injection rate, the pressure drop across the core was monitored continuously as a function of the ionic strength of the aqueous solution flowing through the core. All the Berea sandstone samples used for this study were from the same block, having a initial permeability of approximately $10 \mathrm{mD}$. The cores were not fired nor acidized prior to the experiments. The Berea samples had a clay content of approximately $8 \mathrm{wt} \%$, and $75 \%$ of which is kaolinite clay.

The ionic strength of the solution is decreased in a stepwise manner, and this technique has been used successfully (Khilar, 1981; Khilar and Fogler, 1984) to determine the CSC of various single salt systems. The critical ionic strength is defined as the ionic strength at which there is a sharp decline in the relative

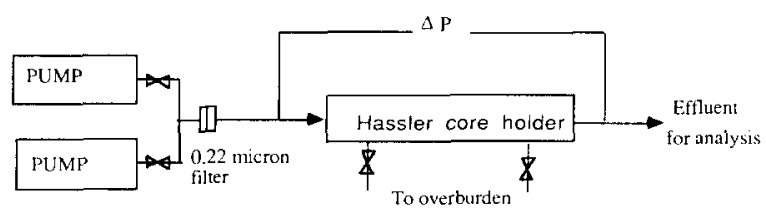

Fig. 1. Experimental equipment.

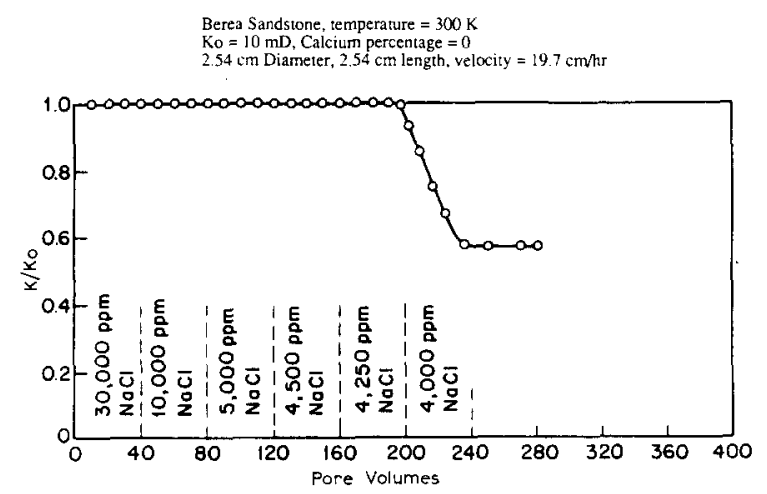

Fig. 2. Measurement of critical ionic strength from relative permeability (Khilar, 1981).

permeability $\left(K / K_{\mathrm{o}}\right)$. A typical measurement is shown in Fig. 2 (Khilar, 1981). The value of the CSC for different cations, such as $\mathrm{Li}^{+}$, $\mathrm{K}^{+}, \mathrm{NH}_{4}^{+}, \mathrm{Cs}^{+}$, have been reported by Khilar (1981). In our present study, the concentrations of the ions $\left(\mathrm{Ca}^{2+}\right.$ and $\left.\mathrm{Na}^{+}\right)$were measured using specific ion electrodes. The particulate content of the effluent was analyzed using an Atomic Absorption Spectrometer (AAS)* and a Scanning Electron Microscope (SEM). The ionic strength at which the pressure drop across the core begins to increase and the clay particles appear in the effluent determines the critical concentration. A similar experimental procedure was used in this work.

In a typical experiment, a Berea sandstone core $(2.54 \mathrm{~cm}$ both in diameter and length) was vacuum saturated with a $\mathrm{NaCl} / \mathrm{CaCl}_{2}$ salt solution of $0.10 \mathrm{M}$ ionic strength (I) and at a particular mole percent of calcium. The saturated Berea sandstone was placed in a core holder and a $\mathrm{NaCl} / \mathrm{CaCl}_{2}$ salt solution was flown through the core at a superficial velocity of $19.2 \mathrm{~cm} \mathrm{~h}^{-1}$ ( $\left.15.1 \mathrm{ft} \mathrm{day}^{-1}\right)$. The temperature was maintained at $30^{\circ} \mathrm{C}$ by means of a constant temperature bath. The inlet $\mathrm{pH}$ was in the range 6-7 while the $\mathrm{pH}$ of the effluent was found to vary between 8 and 9 . As de-

\footnotetext{
${ }^{*}$ The fines that are released were collected and acidized. This solution was then analyzed for $\mathrm{Al}^{3+}$ and $\mathrm{Si}^{4+}$ concentration using an AAS, and therefore estimate the amount of fines released.
} 
Berea sandstone, temperature $=300 \mathrm{~K}$ $\mathrm{Ko}=10 \mathrm{mD}$, Calcium percentage $=5$

$2.54 \mathrm{~cm}$ diameter, $2.54 \mathrm{~cm}$ length

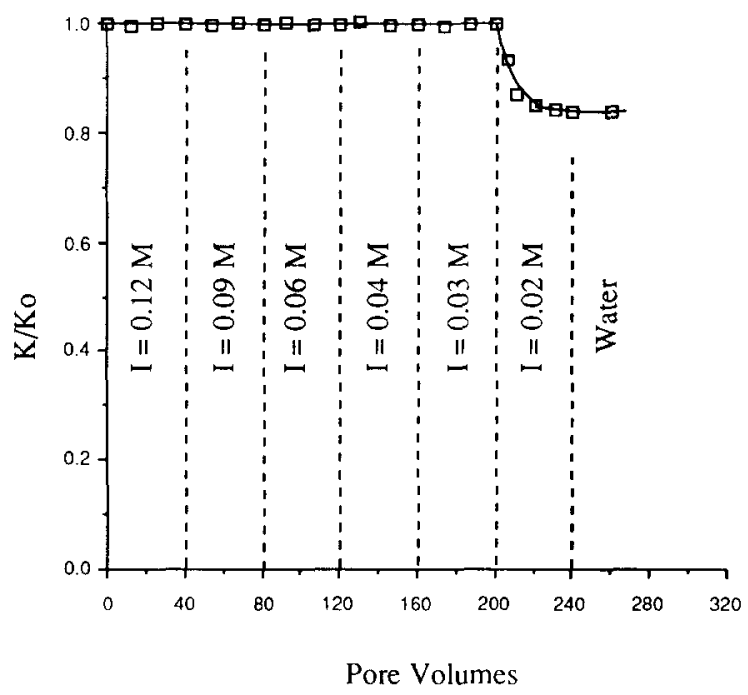

Fig. 3. Measurement of CTIS at 5 mole $\%$ calcium and 95 mole $\%$ sodium.

Berea sandstone, temperature $=300 \mathrm{~K}$

$\mathrm{Ko}=10 \mathrm{mD}$, Calcium percentage $=10$

$2.54 \mathrm{~cm}$ diameter, $2.54 \mathrm{~cm}$ length

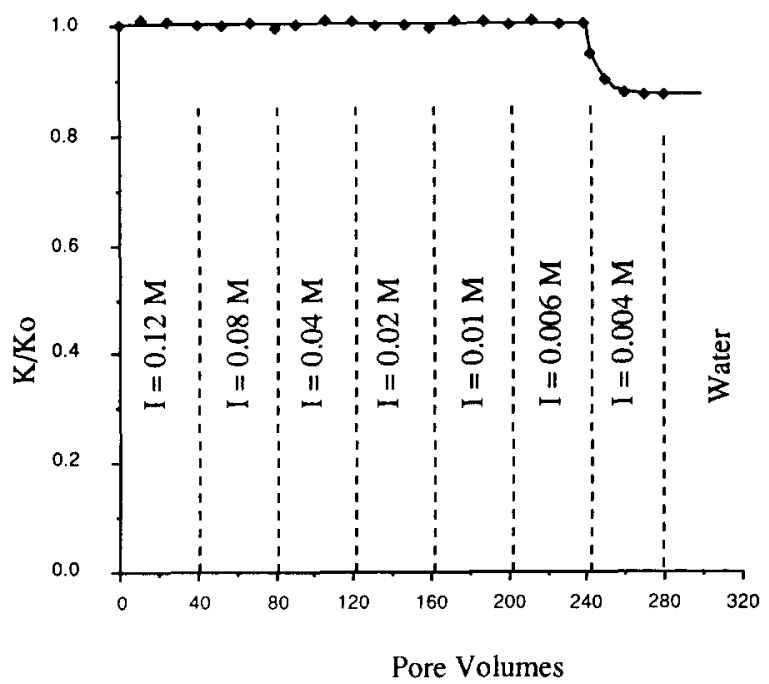

Fig. 4. Measurement of CTIS at 10 mole \% calcium and 90 mole $\%$ sodium.

scribed earlier, the ionic strength of the salt solution was decreased in a step-wise manner, the ionic strength was first decreased by large steps
TABLE 1

$C T I S$ for Berea sandstone at different calcium percentage

\begin{tabular}{rcc}
\hline$\% \mathrm{Ca}$ & $\% \mathrm{Na}$ & $C T I S(M)$ \\
\hline 0 & 100 & 0.071 \\
5 & 95 & 0.025 \\
10 & 90 & 0.005 \\
15 & 85 & $\ll 0.001$ \\
\hline
\end{tabular}

to obtain a range for the CTIS. Having obtained a coarse range, the ionic strength was then decreased in small steps within the range to determine the CTIS with an accuracy of $\pm 0.0005 \mathrm{M}$.

Figures 3 and 4 show the values of $C T I S$ measured at calcium percentages of 5 and 10 , and all the results are summarized in Table 1. One observes from this table that CTIS decreases as the calcium percentage increases. That is, even at low ionic strength the fines are not released at higher calcium percentages. At $15 \%$ calcium $/ 85 \%$ sodium, the CTIS could not be obtained as it appears to be much below the detection limit of the system.

The experimental results can be explained through a qualitative analysis, by comparing the zeta potentials $(\zeta)$ and the consequent variations in the double layer interactions. The zeta potentials of kaolinite and the Berea sandstone are strongly dependent on the extent of surface coverage of $\mathrm{Ca}^{2+}$ ions (Kia et al., 1987b), which in turn depends on the ion exchange equilibria between the particles and the mixed salt solution (Bolt, 1955; Wilemsky, 1982). The ionic condition of the fluid can be described by two parameters: the calcium percentage and the total ionic strength. The reduction in zeta potential with increasing calcium percentage causes the double layer repulsive potential to decrease and decreasing the probability of release. Therefore, the total ionic strength must be reduced to increase the diffuse double layer and increase the probability of release. Consequently, increasing the calcium percentage lowers the CTIS. 


\section{Extension of $C S C$ analysis to estimate $C T I S$}

The DLVO-type of analysis, used earlier by Khilar and Fogler (1984) to estimate the CSC, is extended to study the effects of calcium percentage on CTIS. The total energy $\left(V_{\mathrm{T}}\right)$ and the total force $\left(F_{\mathrm{T}}\right)$ are identically zero at CTIS:

$$
\begin{aligned}
& V_{\mathrm{T}}=0 \\
& \frac{\partial V_{\mathrm{T}}}{\partial h}=0=F_{\mathrm{T}}
\end{aligned}
$$

where, $h$ is the distance of separation between the pore wall and the particle. The total potential $\left(V_{\mathrm{T}}\right)$ can be obtained by simply adding the individual potentials:

$V_{\mathrm{T}}=V_{\mathrm{LVA}}+V_{\mathrm{DLR}}+V_{\mathrm{BR}}+V_{\mathrm{HR}}$

where:

$V_{\text {LVA }}$ London-van der Waals attractive potential;

$V_{\text {DLR }}$ Double layer repulsive potential;

$V_{\mathrm{BR}} \quad$ Born repulsive potential; and

$V_{\mathrm{HR}}$ Hydrodynamic repulsive potential.

It has been shown that, the contribution of the hydrodynamic potential becomes comparable to the colloidal forces only at very high flow-rates, that is superficial velocities greater than $1000 \mathrm{~cm} \mathrm{~h}^{-1}$ (Cerda, 1988). The experimental results of Khilar (1981), listed in Table 2, also show the weak dependence of velocity on the critical salt concentration. Since the experimental velocities in this study were much lower $\left(19.2 \mathrm{~cm} \mathrm{~h}^{-1}\right)$, the effect of $V_{\mathrm{HR}}$ was neglected. When the distance of separation between the particle and the wall is of the

TABLE 2

CSC various superficial velocities (Khilar, 1981)

\begin{tabular}{ll}
\hline $\begin{array}{l}\text { Superficial velocity } \\
\left(\mathrm{cm} \mathrm{h}^{-1}\right)\end{array}$ & $\begin{array}{l}C S C \text { molarity } \\
(M)\end{array}$ \\
\hline 3.15 & $0.072 \pm 0.003$ \\
19.7 & $0.071 \pm 0.002$ \\
568.4 & $0.071 \pm 0.002$ \\
\hline
\end{tabular}

order of $5 \AA$, the Born repulsive potential is comparable in magnitude to London-Van der Waals and Double layer potential. The inclusion of the Born repulsion term makes the primary minimum of the interaction potential finite. The existence of the finite primary minimum has been able to explain the observed adsorption/desorption of particles from surfaces and the flocculation behavior of colloidal suspensions (Hamaker, 1937; Ruckenstein and Prieve, 1976; Feke et al., 1984). Equation 3 reduces to:

$V_{\mathrm{T}}=V_{\mathrm{LVA}}+V_{\mathrm{BR}}+V_{\mathrm{DLR}}$

Some investigators have modeled clay/clay interactions as either having a plate/plate or a cylinder/plate geometry (James and Williams, 1982). Typically, the clay particles are the order of one micron size and the pore to which they are attached have diameters approximately $30-40$ microns. Therefore, the interaction between the particle (kaolinite clay) and the sandstone surface (Berea) were modeled to have a sphere/plate geometry as done by previous investigators (Khilar, 1981; Sharma et al., 1985). For such a system the London-Van der Waals potential is given by (Ruckenstein and Prieve, 1976):

$V_{\mathrm{LVA}}=\frac{A}{6}\left[\ln \left(\frac{h+2 a}{h}\right)-\frac{2 a}{h}\left(\frac{h+a}{h+2 a}\right)\right]$

where $A$ is the Hamaker constant, $a$ is the radius of the particle, and $h$ is the distance of separation.

The double layer potential can be calculated, under certain approximations, using the following expression of Ruckenstein and Prieve (1976):

$$
V_{\mathrm{DLR}}=16 \epsilon\left(\frac{k T}{e}\right)^{2} a \tanh \left(\frac{y_{1}}{4}\right) \tanh \left(\frac{y_{2}}{4}\right) \mathrm{e}^{-\kappa h}
$$


where:

$I=\frac{1}{2} \sum n_{i}^{0} z_{i}^{2}$

$\kappa^{2}=\left(\frac{8 \pi e^{2} I}{\epsilon k T}\right)$

$y_{j}=\frac{\epsilon \Psi_{j}}{k T}$

In these expression:

$n_{i}^{0} \quad$ bulk concentration of species, $i$

$\Psi_{j} \quad$ surface potential of surface, $j(j=1,2)$

$z_{i} \quad$ valency of species, $i$

$e \quad$ electronic charge

$I$ total ionic strength

$k$ Boltzmann's constant

$T$ absolute temperature

$\epsilon$ permittity of the medium (all in cgs units )

The Born repulsion potential $\left(V_{\mathrm{BR}}\right)$, accounts for the short range structural or hydration forces due to the interaction of particles with adsorbed fluid layers (Feke et al., 1984). Assuming that these interactions can be linearly superimposed, Ruckenstein and Prieve (1976) obtained the following formula for a sphere-plate interaction geometry:

$V_{\mathrm{BR}}=-\frac{A \sigma}{7560}\left[\frac{8 a+h}{(2 a+h)^{7}}+\frac{6 a-h}{(h)^{7}}\right]$

Here $\sigma$, is the collision diameter, and is approximately 5-6

The ionic strength and the calcium percentage (\%Ca) are related to the molarities of $\mathrm{Na}^{+}$ and $\mathrm{Ca}^{2+}\left(M_{\mathrm{Na}}\right.$ and $\left.M_{\mathrm{Ca}}\right)$ in the following manner:

$I=M_{\mathrm{Na}}+3 M_{\mathrm{Ca}}$

$\% \mathrm{Ca}=100\left(\frac{2 M_{\mathrm{Ca}}}{M_{\mathrm{Na}}+2 M_{\mathrm{Ca}}}\right)$

The total energy of interaction $V_{\mathrm{T}}$ was calculated by using Eqs. 3-6. The total energy of interaction may be evaluated as a function of the separation distance $h$ for different values of ionic strength and at various calcium percentages.
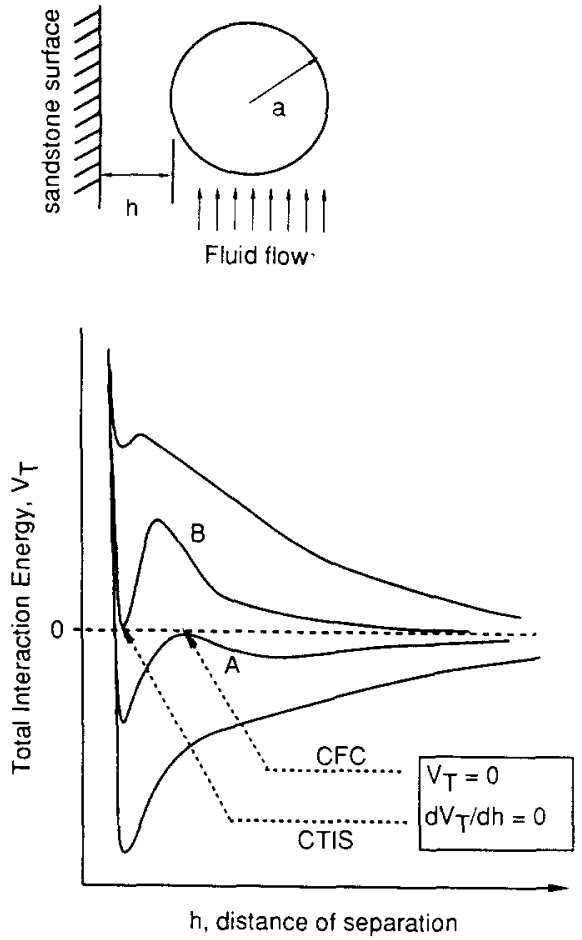

lonic strength of $A$ is greater than ionic strength of $B$

Fig. 5. Interaction potentials showing the critical ionic strength.

The value of CTIS is determined as the value of the ionic strength $I$ for which both the magnitude and the slope of the $V_{\mathrm{T}} / k T$ versus $h$ plot become zero at some distance of separation (Eqs. 1 and 2). Figure 5 shows some typical interaction profiles that may be realized from Eqs. 3-6. One observes, that there is more than one situation when the conditions of Eqs. 1 and 2 are satisfied. The first situation arises when the maximum of the interaction potential curve satisfies the above conditions, and is shown as curve $A$. This salt concentration is generally referred to as the critical flocculation concentration $(C F C)$ in colloidal studies related to aggregation of particles. As can be observed from Fig. 5, the primary minimum is still negative compared to the bulk potential (which is zero), and therefore the escape of particles from the primary minimum is minimal. 
Reducing the ionic strength below the $C F C$ results in the second situation, when the primary minimum satisfies the conditions of Eqs. 1 and 2 . This is shown by curve B in Fig. 5 . This ionic strength will be referred to as the critical total ionic strength (CTIS). Lowering the ionic strength below the CTIS makes the value of the potential at the primary minimum greater than the bulk potential. This condition now favors the detachment (or escape) of the particles from the primary minimum. The presence of a maximum in the interaction potential can slow the rate of release, since the particles have to diffuse over a potential barrier. For some ionic conditions, a secondary minimum may also be present and this could also have an effect on the rate of adsorption and desorption of particles (Ruckenstein, 1978 ). This effect results because the particles that are released form the primary minimum diffuse over the potential barrier and under certain circumstances may be captured in the secondary minimum, thus reducing release rates. From the above discussion, however, it is evident that, ionic strengths below CTIS will lead to the detachment of the clay fines from the sandstone surface. These released fines will diffuse into the bulk and flow with the fluid, consequently leading to formation damage.

Figures 6 and 7 show the total energy of interactions $V_{\mathrm{T}}$ as a function of distance of separation $h$ for different values of total ionic strength $I$ at 5 and $10 \%$ calcium percentage.

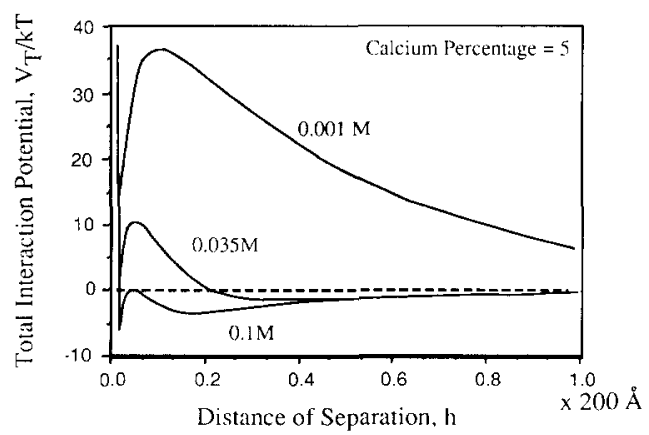

Fig. 6. Total interaction potential for different ionic strengths and $5 \%$ calcium in solution.
The values of zeta potentials were taken from the literature and at the calcium percentage of 5 and 10 , the zeta potentials of kaolinite are approximately -16 and $-12 \mathrm{mV}$, respectively, and those of Berea sandstone at -18 and $-14 \mathrm{mV}$, respectively (Kia et al., 1987a, $1987 \mathrm{~b})$. The variation of zeta potential with total ionic strength (excluding the variations at very low values of $I$ ) was found to be very weak (Kia et al., 1987a) and was neglected in the calculations. A Hamaker's constant, $A$, of $0.6 \times 10^{-13}$ ergs, which lies in the reported range of $0.30-6.0 \times 10^{-13}$ ergs for clay-sandstone systems (Lyklema, 1968), was found to fit the observed experimental data satisfactorily.

The variations of interaction potential with the distance of separation and for different ionic strengths can be observed from any of these two figures. One observes from Fig. 6, the total interaction potential is negative or attractive (no release condition) at high values of ionic strength, while the potential is positive or repulsive (favoring release) at lower ionic strengths of the order of $0.001 \mathrm{M}$.

The variation of total potential with distance of separation $h$ follows the common trend of decrease in attractive energy as separation distance increases and the occurrence of maximum and minimum depending on the value of the zeta potential, ionic strength and Hamaker's constant. Comparing Figs. 6 and 7, one observes that for the same value of ionic

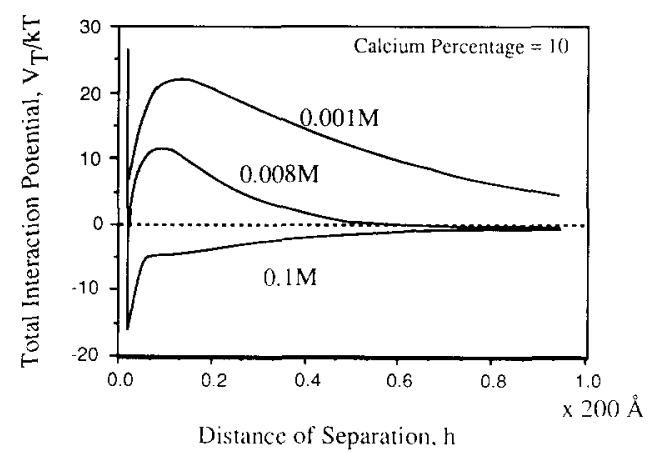

Fig. 7. Total interaction potential for different ionic strengths and $10 \%$ calcium in solution. 
TABLE 3

Comparison of $C F C$ and $C T I S$ at various calcium percentages

\begin{tabular}{rlll}
\hline \% Ca & $C F C(M)$ & $\begin{array}{l}C T I S(M) \\
\text { (experimental }\end{array}$ & $\begin{array}{l}\text { CTIS }(M) \\
\text { (predicted) }\end{array}$ \\
\hline 0 & 0.12 & 0.071 & 0.071 \\
5 & 0.1 & 0.025 & 0.035 \\
10 & 0.032 & 0.005 & 0.008 \\
\hline
\end{tabular}

strength $I$, the interaction potential $V_{\mathrm{T}}$ is more negative (increased attraction) at higher calcium percentages and decreases (becomes negative) with an increase in ionic strength.

One also observes from these figures that $C T I S$ at 5 and $10 \%$ calcium can be taken equal to 0.035 and 0.008 , respectively. These corresponding values calculated from DLVO theory compare well with the measured values of 0.025 and $0.005 \mathrm{M}$. For $15 \% \mathrm{Ca} / 85 \% \mathrm{Na}$ the calculations showed that even at a low ionic strength of $0.001 \mathrm{M}$, the total energy of interactions is negative and hence the CTIS is below 0.001 $M$. The values in Table 3 give the ionic strength for the $C F C$ and the CTIS, as has been defined previously, for various calcium percentages. As discussed earlier, an increase in concentration beyond the $C F C$ enhances flocculation, while decreasing below the CTIS favors peptization (or detachment) of particles.

Although this very good agreement of theoretical predictions with data may be somewhat fortuitous, we wish to caution that the quantitative agreement depends on the estimated Hamaker's constant, which can be determined accurately with great difficulty. Therefore like most other analyses based on the DLVO theory, this analysis can be considered as semiquantitative predicting the relative change in $C T I S$ at different colloidal conditions for $a$ mixed salt system.

\section{Conclusions}

It can be concluded from the presented measurements and analysis that a critical total ionic strength (CTIS) for a mixed salt system of $\mathrm{NaCl} / \mathrm{CaCl}_{2}$ flowing through Berea sandstone exists, below which fines are released due to colloidal forces. The value of CTIS is strongly dependent on the relative amount of $\mathrm{CaCl}_{2}$ present in the solution. For calcium molar percentage of 15 or higher, the molarity of the CTIS is virtually zero, while the maximum value $(0.07 \mathrm{M})$ is at zero calcium percentage. Analysis based on the DLVO theory agree reasonably well with measurements. Although this study has been conducted for Berea- $\mathrm{NaCl} /$ $\mathrm{CaCl}_{2}$ system, the measurement technique and the analysis developed can be applied to other systems as well.

\section{Acknowledgements}

One of the authors, $\mathrm{KCK}$, thanks the Department of Science and Technology, New Delhi, India for financial support (Sanction No. DST/STP/83/III) to carry out a part of this work. In addition KCK acknowledges with thanks the summer visiting faculty position offered by the department of Chemical Engineering at The University of Michigan. We also gratefully acknowledge the support from the National Science Foundation grant No. CBT8516458 .

\section{References}

Bolt, G.H., 1955. Ion adsorption by clays.Soil Sci., 79: 267. Cerda, C.M., 1988. Mobilization of quartz fines in porous media. Clays Clay Miner., 36 (6): 491.

Grim, R.E., 1968. Clay Mineralogy, McGraw Hill, New York, N.Y., p. 596.

Erickson, E., 1952. Cation-exchange equilibria on clay minerals. Soil Sci., 74: 103.

Feke, D.L., Prabhu, N.D., Mann, Jr., J.A. and Mann, III, J.A., 1984. A formulation of the short-range repulsion between spherical colloidal particles. J. Phys. Chem., 88 (23): 737 .

Hamaker, H.C., 1937. A general theory of lyophobic colloids. II. Rec. Trav. Chim., 56 (1): 3.

Hardcastle, J.H. and Mitchell, J.K., 1974. Electrolyte concentration - permeability relationships in sodium-illite silt mixtures. Clays Clay Miner., 22 (2): 143. 
Hiemenz, P.C., 1986. Principles of Colloid and Surface Chemistry, 2nd ed., Marcel Dekker, New York, N.Y., pp. 717-721.

James, A.E. and Williams, D.J.A., 1982. Particle interactions and rheological effects in kaolinite suspensions, Adv. Colloid Interface Sci., 17: 219.

Jones, F.O., Jr., 1964. Influence of chemical composition of water on clay blocking of permeability. J. Pet. Technol., (Ap.): 441.

Khilar, K.C., 1981. The water sensitivity of Berea Sandstone. Ph.D. thesis, The University of Michigan, Ann Arbor, Mich.

Khilar, K.C. and Fogler, H.S., 1984. The existence of a critical salt concentration for particle release. J. Colloid Interface Sci., 101: 214.

Khilar, K.C. and Fogler, H.S., 1987. Colloidally induced fines migration in porous media. Rev. Chem. Eng., 4: $(1 / 2) 41$.

Khilar, K.C., Fogler, H.S. and Gray, D.H., 1985. Model for piping-plugging in earthen structures. ASCE, J. Geotech. Eng. Div., 111: (7) 833.

Kia, S.F., Fogler, H.S. and Reed, M.G., 1987a. Effect of $\mathrm{pH}$ on colloidally induced fines migration. J. Colloid Interface Sci., 118 (1): 158.

Kia, S.F., Fogler, H.S., Reed, M.G. and Vaidya, R.N., 1987b. Effect of salt composition on clay release in Berea Sandstones. S.P.E. 16254, Production Engineering, (Nov.) 277.
Kolakowski, J.E. and Matijevic, E., 1979. Particle adhesion and removal in model systems. J. Chem. Soc. Faraday Trans. I., 75 (1): 65.

Lyklema, J., 1968. Principles of the stability of lyophobic colloidal dispersions in non-aqueous media. Adv. Colloid Interface Sci., 2: 65 .

Quirk, J.P. and Schofield, R.K., 1955. The effect of electrolyte concentration on soil permeability. J. Soil Sci., $6(2): 163$.

Rowel, D.L., Payne, D. and Ahmad, N., 1969. The effect of the concentration and movement of solutions on the swelling, dispersion, and movement of clay in saline and alkali soils. J. Soil Sci., 20 (1): 176.

Ruckenstein, E., 1978. Reversible rate of adsorption or coagulation of Brownian particles-Effect of the shape of the interaction potential. J. Colloid Interface Sci., 66 (3): 531.

Ruckenstein, E. and Prieve, D.C., 1976. Adsorption and desorption of particles and their chromatographic separation, AIChEJ., 22 (2): 276.

Sharma, M.M., Yortsos, Y.C. and Handy, L.L., 1985. Release and deposition of clays in sandstones. SPE 13562, Int. Symp. Oilfield and Geothermal Chem., Phoenix, Ariz.

Wilemsky, G., 1982. Weak repulsive interactions between dissimilar electrical double layers. J. Colloid Interface Sci., 88(1): 111. 